06

\title{
Нанокомпозиты бор-углерод, созданные воздействием высоких давлений и высоких температур
}

\author{
(C) P.Х. Баграмов, ${ }^{1}$ H.P. Серебряная, ${ }^{1,2}$ B.М. Прохоров, ${ }^{1,2}$ В.Д. Бланк ${ }^{1,2,3}$ \\ ${ }^{1}$ Технологический институт сверхтвердых и новых углеродных материалов, \\ 142190 Москва, Троицк, Россия \\ ${ }^{2}$ Московский ффизико-технический институт, \\ 141700 Долгопрудный, Московская обл., Россия \\ ${ }^{3}$ Национальный исследовательский технологический университет „МИСИС“, \\ 119049 Москва, Россия \\ e-mail: bagramov@tisnum.ru
}

(Поступило в Редакцию 3 ноября 2017 г.)

\begin{abstract}
Приведены результаты исследования взаимодействия аморфного бора и фуллерита $\mathrm{C}_{60}$ при заданных давлениях 2.0 и $7.7 \mathrm{GPa}$ и температурах $600-1800^{\circ} \mathrm{C}$. Установлено влияние параметров термобарической обработки на структуру получаемых материалов, определены температуры синтеза карбида бора и алмаза, а также последовательность превращений углеродной составляющей. Ультразвуковым методом измерены упругие модули образцов, проанализирована их зависимость от структуры. Установлено, что бор-углеродный нанокомпозит, синтезированный при относительно низких параметрах $2.0 \mathrm{GPa} \mathrm{и} \sim 1000^{\circ} \mathrm{C}$, обладает достаточно высокими упругими характеристиками: модуль объемного сжатия $B \approx 75.3-84.0 \mathrm{GPa}$, модуль Юнга $E \approx 108-119 \mathrm{GPa}$, модуль сдвига $G \approx 43-47 \mathrm{GPa}$, при плотности $\approx 2.2 \mathrm{~g} / \mathrm{cm}^{3}$. Полученные результаты могут быть использованы при разработке новых нанокомпозитных материалов.
\end{abstract}

DOI: $10.21883 /$ JTF.2018.07.46174.2545

\section{Введение}

Новые формы углерода, такие как фуллериты, нанотрубки и наноалмазы, в настоящее время находят все более широкое применение при разработке новых (объемных) композитных материалов [1]. Ожидается, что эксплуатационные свойства таких материалов значительно улучшатся, если в них будет создана специальная наноструктура.

Система бор-углерод перспективна в качестве основы новых композитов. Наиболее распространенное соединение, карбид бора $\left(\mathrm{B}_{4} \mathrm{C}\right)$, занимает третье место по твердости после алмаза и нитрида бора. Оно имеет высокие значения прочности, сопротивления износа и упругих модулей, повышенные химическую стойкость и температурную стабильность, высокую теплопроводность. Карбид бора $\mathrm{B}_{4} \mathrm{C}$ используется в инструментах для механической обработки, защитных и износоустойчивых покрытиях, соплах водноабразивной резки, фильерах, футеровке и размольных телах мельниц и в других продуктах.

Для создания наноструктурированных композитов в качестве наноструктурирующей компоненты перспективно использовать фуллерит $\mathrm{C}_{60}$. Под воздействием высоких давлений и температур $\mathrm{C}_{60}$ формирует структуры со свойствами, изменяющимися в широком диапазоне, ряд из которых обладает исключительной твердостью [2]. Некоторые из них проявляют значительную эластичность, т.е. способность восстанавливать свою форму после снятия нагрузки [3,4]. К ним относятся и вещества с так называемой фуллереноподобной (или луко- вичной) структурой, которые одновременно могут иметь модуль Юнга 50-65 GPa и твердость 8-12 GPa [5]. Фуллереноподобными было предложено называть структуры, состоящие из изогнутых, графитоподобных взаимосвязанных фрагментов [6]. Насколько нам известно, исследования, направленные на создание такого типа структуры в объемных керамических материалах на основе бора (или карбида бора), до настоящего времени не проводились.

В настоящей работе для создания наноструктурированных бор-углеродных композитов использовался метод высоких давлений и температур (ВДВТ) [7], который, как было упомянуто, используется для получения новых фаз из фуллерита $\mathrm{C}_{60}$. Кроме того, известно, что без использования давлений получить материал без пор при спекании бора и углерода невозможно [8].

Исследования были нацелены на установление взаимосвязи структуры и упругих модулей нанокомпозитов, получаемых при ВДВТ воздействии на систему $\mathrm{B}+\mathrm{C}_{60}$.

\section{Материалы и методы исследования}

В качестве исходных были выбраны: аморфный бор (круглые частицы размером до $2 \mu \mathrm{m}$, ТУ 6-02-1333-80) и фуллерит $\mathrm{C}_{60}(99.98 \%$ чистоты, производства компании „Фуллерен Центр“, Нижний Новгород, Россия).

Исходные материалы тщательно смешивались вручную в яшмовой ступке в атомном соотношении $\mathrm{B}: \mathrm{C}=2$ (состав - 31 wt. $\% \mathrm{~B}+69$ wt. $\left.\% \mathrm{C}_{60}\right)$.

Для получения компактных образцов были выбраны два давления 2.0 и $7.7 \mathrm{GPa}$ и диапазон температур 
$600-1800^{\circ} \mathrm{C}$. Выбор параметров термобарической обработки обусловлен тем, что давление $7.7 \mathrm{GPa}$ и диапазон температур $600-1800^{\circ} \mathrm{C}$ соответствует области термодинамической стабильности алмаза, а при $2.0 \mathrm{GPa}$ и выбранных температурах алмаз термодинамически неустойчив [9].

Для обработки порошковой $\mathrm{B}+\mathrm{C}_{60}$ смеси использовалось ВДВТ оборудование с камерой высокого давления „тороид“ [7]. Смесь изолировалась танталовой фольгой и помещалась внутрь графитового нагревателя внутри контейнера из литографского камня. Для создания давления такая сборка сдавливалась между профилированными твердосплавными наковальнями камеры „тороид“ в прессе ДО-138. Нагрев обеспечивался прямым пропусканием электрического тока через графитовый нагреватель. Для измерения температуры использовались термопары: хромель-алюмель до $1200^{\circ} \mathrm{C}$, платина-платина-родий до $1600^{\circ} \mathrm{C}$ и вольфрам-рений для более высоких температур. Погрешность измерения была не более $25^{\circ} \mathrm{C}$. Калибровка давления проводилась при комнатной температуре с использованием общепринятой методики регистрации скачков электрического сопротивления, сопровождающих фазовые переходы эталонных веществ [10].

Структурные исследования материалов после ВДВТ обработки проводили методами рентгеновской дифрактометрии (дифрактометр ARL X'TRA, $\mathrm{Cu} K_{\alpha}$-излучение), сканирующей (СЭМ) и просвечивающей (ПЭМ) электронной микроскопии (микроскопы JSM-7 600F и ЈЕМ-2010).

Для измерения упругих свойств ультразвуковым методом из прошедших ВДВТ обработку заготовок были изготовлены цилиндрические образцы диаметром $\sim 2 \mathrm{~mm}$ и высотой $2.25-3.30 \mathrm{~mm}$. Противоположные концы цилиндров были отшлифованы и отполированы. Скорости продольных $\left(V_{L}\right)$ и сдвиговых $\left(V_{T}\right)$ ультразвуковых волн были измерены с использованием методов лазерного возбуждения (прибор УДЛ-2М, компания „ОК ВИНФИН“, Россия) и акустической микроскопии (широкополосный акустический микроскоп WFAM, ИБХФ им. Н.М. Эммануэля РАН, Россия). Отметим, что обе методики позволяют возбуждать ультразвуковые волны и измерять их скорости локально с поверхности [11]. Из-за упругой неоднородности прошедших ВДВТ обработку образцов, измеренные значения усреднялись как для локальных измерений одного образца, так и для двух образцов, полученных при одинаковой температуре. Погрешность ультразвуковых измерений скорости упругих волн была не более $1.5 \%$.

Плотность образцов измеряли методом Архимеда с помощью весов Kern-770-60 с приставкой для измерений плотности Sartorius YDK 01 LP. Погрешность измерений не превышала $\pm 0.1 \mathrm{~g} / \mathrm{cm}^{3}$.

Упругие модули рассчитывались на основе соответствующих значений скоростей продольных и сдвиговых ультразвуковых волн и значений плотности образцов.

\section{Результаты и обсуждение}

Дифрактограммы образцов, полученных из смеси $\left(31 \mathrm{wt} . \% \mathrm{~B}+69 \mathrm{wt} . \% \mathrm{C}_{60}\right)$ при давлении $2.0 \mathrm{GPa}$ и различных температурах, представлены на рис. 1. Их ана-

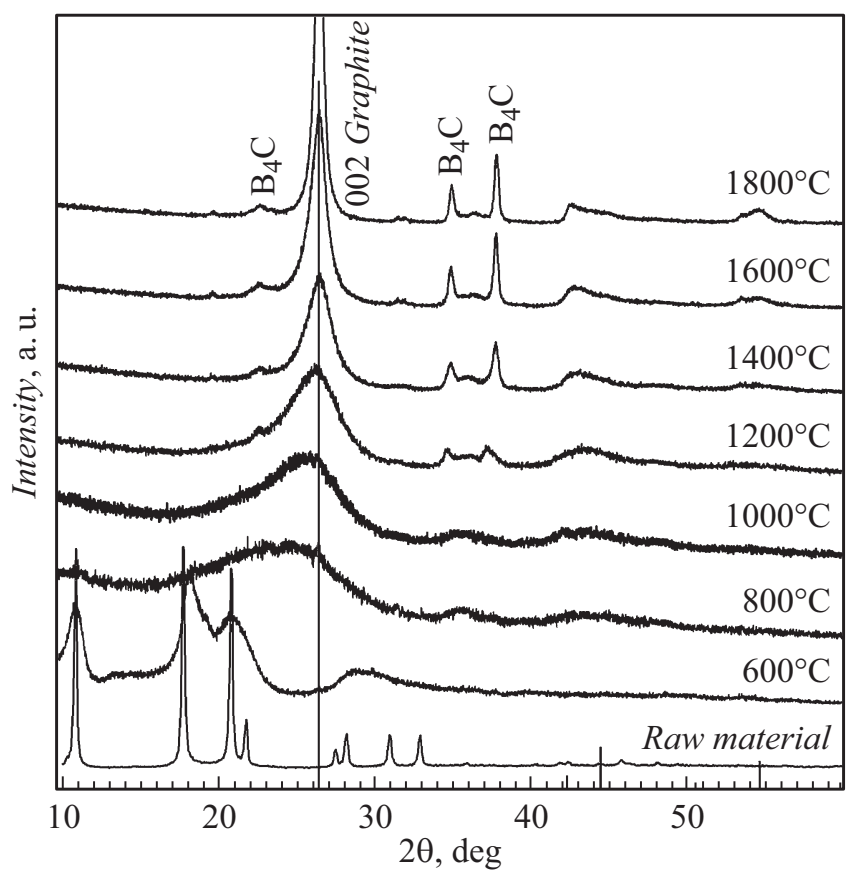

Рис. 1. Дифрактограммы образцов, полученных из смеси $31 \mathrm{wt} . \% \mathrm{~B}+69$ wt.\% $\mathrm{C}_{60}$ при $2.0 \mathrm{GPa}$ и различных температурах. Вертикальные линии обозначают дифракционные отражения графита, приведенные в базе данных PDF 00-041-1487, ICDD.

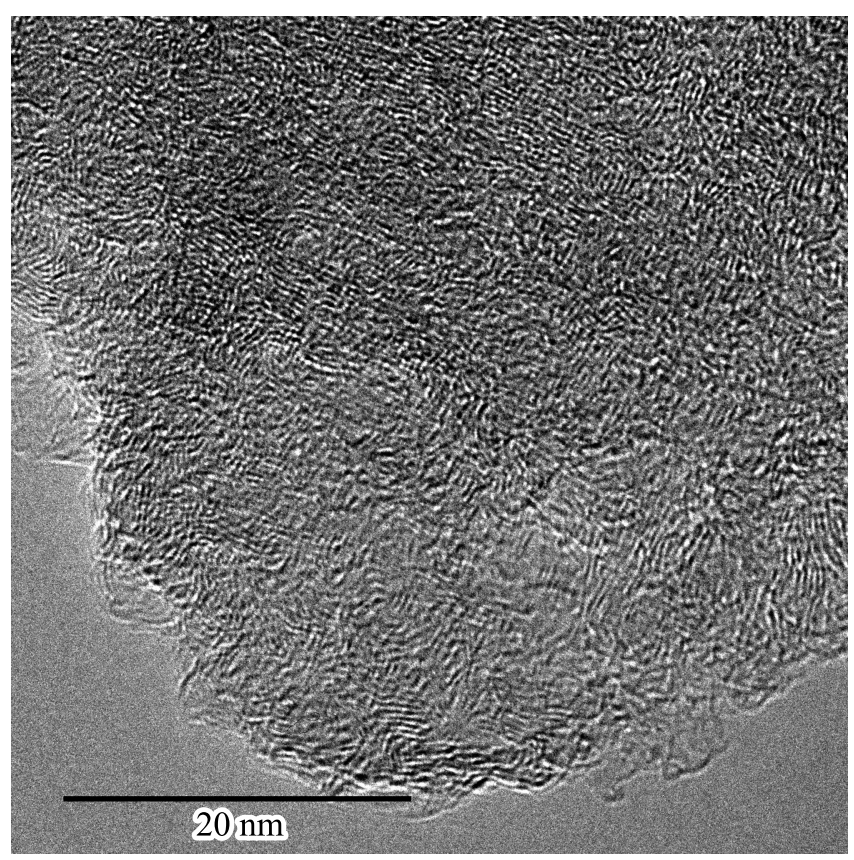

Рис. 2. Углеродная структурная составляющая образца, полученного из $31 \mathrm{wt} . \% \mathrm{~B}+69 \mathrm{wt} . \% \mathrm{C}_{60}$ при $2.0 \mathrm{GPa} / 100{ }^{\circ} \mathrm{C}$, состоящая из изогнутых фрагментов с характерным размером менее $5 \mathrm{~nm}$. 


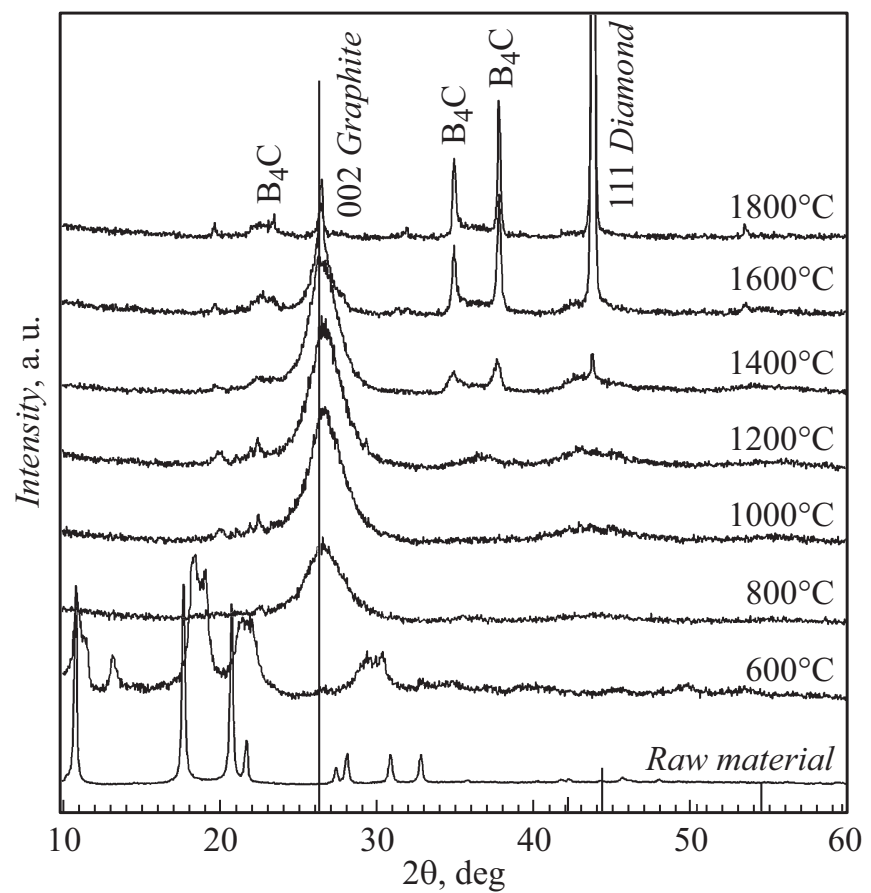

Рис. 3. Дифрактограммы образцов, полученных из смеси $31 \% \mathrm{~B}+69 \% \mathrm{C}_{60}$ при $7.7 \mathrm{GPa}$ и различных температурах. Вертикальные линии обозначают дифракционные отражения графита, приведенные в базе данных PDF 00-041-1487, ICDD.

лиз позволяет сделать вывод, что повышение температуры приводит к превращениям фуллерита $\mathrm{C}_{60}$ по схеме $\mathrm{C}_{60} \rightarrow$ разупорядоченный углерод. При этом при температуре $800-1000^{\circ} \mathrm{C}$ фуллерит $\mathrm{C}_{60}$ превращался в разупорядоченную углеродную фазу, которая имеет широкий дифракционный пик, смещенный в сторону меньших углов от положения 002 пика графита, и соответствующее среднее межплоскостное расстояние на $8-11 \%$ больше, чем у графита. Дальнейшее повышение температуры сужает пик и смещает его к 002 отражению графита, что свидетельствует об упорядочении структуры. На рис. 2 представлено ПЭМ изображение углеродной составляющей образца, полученного термобарической обработкой с параметрами $2.0 \mathrm{GPa} / 1000^{\circ} \mathrm{C}$. Структура состоит из деформированных криволинейных областей с характерным размером менее $5 \mathrm{~nm}$. Такую структуру, по-видимому, можно охарактеризовать как совокупность фуллереноподобных фрагментов [5] или как фуллереноподобную структуру [6].

На основании дифрактограмм (рис. 1) можно судить о взаимодействии бора и углерода при давлении $2.0 \mathrm{GPa}$. Начиная с температуры $800^{\circ} \mathrm{C}$, наблюдается широкое гало в области $2 \theta=35-37^{\circ}$. При температуре $1200^{\circ} \mathrm{C}$ оно начинает трансформироваться в широкие дифракционные пики карбида бора, которые сужаются при более высоких температурах. При температуре $1800^{\circ} \mathrm{C}$ материал состоит из карбида бора $\mathrm{B}_{4} \mathrm{C}$ и относительно упорядоченного графитоподобного углерода.
Из анализа дифрактограмм, представленных на рис. 3, фуллерит $\mathrm{C}_{60}$ при $7.7 \mathrm{GPa}$ следует схеме превращения $\mathrm{C}_{60} \rightarrow$ разупорядоченный углерод $\rightarrow$ алмаз. При этом при температуре $800^{\circ} \mathrm{C}$ появляется фаза, которая имеет широкие дифракционные максимумы (рис. 3), первый из которых смещен в сторону больших углов по сравнению с пиком графита 002. По мере увеличения температуры синтеза эти пики перемещаются в „графитовые“ позиции и сужаются. При $\sim 1400^{\circ} \mathrm{C}$ на дифрактограммах появляется самый сильный пик 111 алмаза (рис. 3). При температуре $1600^{\circ} \mathrm{C}$ и выше преобладает алмазная углеродная фаза, хотя неалмазный углерод по-прежнему присутствует в незначительных количествах.

В результате взаимодействия бора и углерода при давлении $7.7 \mathrm{GPa}$ и температуре $1200^{\circ} \mathrm{C}$ на дифрактограмме появляется гало в области $2 \theta=35-37^{\circ}$. При более высоких температурах $\sim 1400^{\circ} \mathrm{C}$ в этой области появляются пики карбида бора $\mathrm{B}_{4} \mathrm{C}$. Количество $\mathrm{B}_{4} \mathrm{C}$ увеличивается с дальнейшим увеличением температуры. При $1800^{\circ} \mathrm{C}$ материал состоит из матрицы $\mathrm{B}_{4} \mathrm{C}$ с внедренными в нее частицами алмаза с размером менее $1 \mu \mathrm{m}$, часть из которых находится в виде друз (рис. 4). Разупорядоченная (графитоподобная) углеродная фаза тем не менее также присутствует в незначительных количествах.

Результаты измерений плотности и упругих модулей образцов, полученных из смеси (31 wt.\% В + + 69 wt.\% $\mathrm{C}_{60}$ ) при $2.0 \mathrm{GPa}$, представлены в табл. 1. Плотность постепенно увеличивается с 1.96 до $2.31 \mathrm{~g} / \mathrm{cm}^{3}$ при повышении температуры синтеза от 600 до $1800^{\circ} \mathrm{C}$. Значения упругих модулей имеют максимумы при $800-1000^{\circ} \mathrm{C}$ : объемный модуль $B=75.3-84.0 \mathrm{GPa}$, модуль Юнга $E=108-119 \mathrm{GPa}$ и модуль сдвига $G=43-47 \mathrm{GPa}$.

Результаты измерений упругих свойств образцов, полученных из смеси (31 wt.\% B + 69wt.\% $\mathrm{C}_{60}$ ) при более

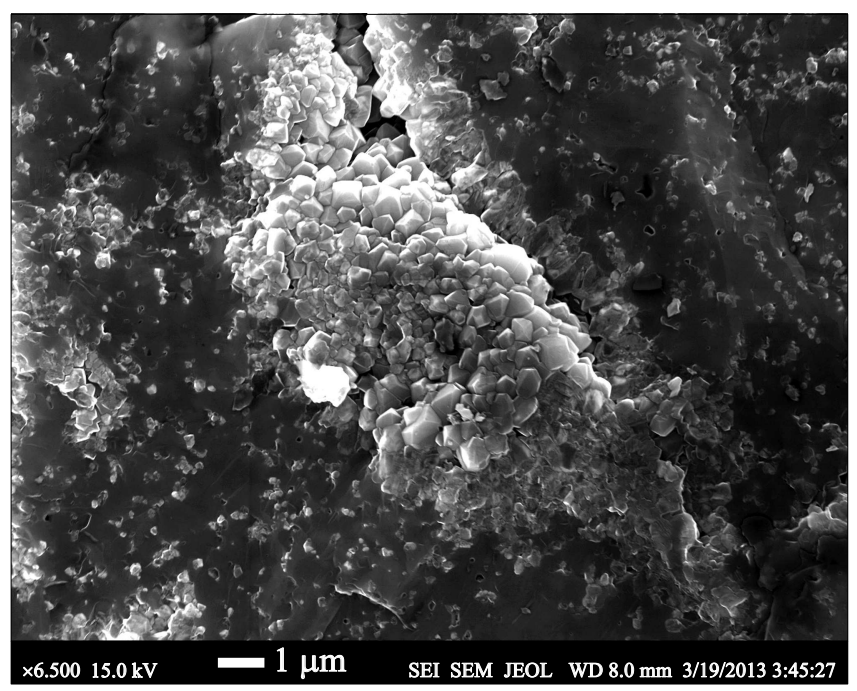

Рис. 4. СЭМ изображение поверхности скола образца, полученного из 31 wt. $\% \mathrm{~B}+69$ wt. $\% \mathrm{C}_{60}$ при $7.7 \mathrm{GPa} / 1800^{\circ} \mathrm{C}$. 
Таблица 1. Плотность $\rho$, скорости звука $V_{L}$ и $V_{T}$, объемный модуль $B$, модуль Юнга $E$, модуль сдвига $G$, коэффициент Пуассона $\sigma$-образцов, полученных из $31 \% \mathrm{~B}+69 \% \mathrm{C}_{60}$ при $2.0 \mathrm{GPa}$

\begin{tabular}{c|c|c|c|c|c|c|c}
\hline $\begin{array}{c}\text { Температура } \\
\text { синтеза, }{ }^{\circ} \mathrm{C}\end{array}$ & $\begin{array}{c}\rho( \pm 0.005), \\
\mathrm{g} / \mathrm{cm}^{3}\end{array}$ & $\begin{array}{c}V_{L}( \pm 0.06), \\
\mathrm{km} / \mathrm{s}\end{array}$ & $\begin{array}{c}V_{T}( \pm 0.03), \\
\mathrm{km} / \mathrm{s}\end{array}$ & $\begin{array}{c}B( \pm 0.8), \\
\mathrm{GPa}\end{array}$ & $\begin{array}{c}E( \pm 0.8), \\
\mathrm{GPa}\end{array}$ & $\begin{array}{c}C_{44}=G( \pm 0.4), \\
\mathrm{GPa}\end{array}$ & $\begin{array}{c}\sigma \\
( \pm 0.004)\end{array}$ \\
\hline 600 & 1.96 & 4.70 & 2.58 & 26 & 33.6 & 13.1 & 0.284 \\
800 & 2.04 & 8.47 & 4.8 & 84 & 119 & 47.1 & 0.263 \\
1000 & 2.14 & 7.87 & 4.48 & 75.3 & 108.4 & 43.0 & 0.261 \\
1200 & 2.19 & 7.32 & 4.25 & 64.6 & 98.6 & 39.6 & 0.245 \\
1400 & 2.26 & 6.92 & 3.68 & 67.5 & 102 & 30.6 & 0.248 \\
1600 & 2.28 & 6.74 & 4.00 & 55.1 & 89.8 & 36.5 & 0.230 \\
1800 & 2.31 & 5.28 & 3.20 & 32.8 & 57.3 & 23.7 & 0.209
\end{tabular}

Таблица 2. Плотность $\rho$, скорости звука $V_{L}$ и $V_{T}$, объемный модуль $B$, модуль Юнга $E$, модуль сдвига $G$, коэффициент Пуассона $\sigma$-образцов, полученных из $31 \% \mathrm{~B}+69 \% \mathrm{C}_{60}$ при $7.7 \mathrm{GPa}$

\begin{tabular}{c|c|c|c|c|c|c|c|c}
\hline $\begin{array}{c}\text { Температура } \\
\text { синтеза, }{ }^{\circ} \mathrm{C}\end{array}$ & $\begin{array}{c}\rho( \pm 0.03), \\
\mathrm{g} / \mathrm{cm}^{3}\end{array}$ & $\begin{array}{c}V_{L}( \pm 0.06), \\
\mathrm{km} / \mathrm{s}\end{array}$ & $\begin{array}{c}V_{T}( \pm 0.03), \\
\mathrm{km} / \mathrm{s}\end{array}$ & $\begin{array}{c}B( \pm 1), \\
\mathrm{GPa}\end{array}$ & $\begin{array}{c}E( \pm 1), \\
\mathrm{GPa}\end{array}$ & $\begin{array}{c}C_{44}=G( \pm 0.4), \\
\mathrm{GPa}\end{array}$ & $\begin{array}{c}\sigma \\
( \pm 0.004)\end{array}$ \\
\hline 600 & \multicolumn{7}{c}{ Материал не удалось скомпактировать } \\
800 & \multicolumn{7}{c}{ Материал не удалось скомпактировать } \\
1000 & 2.19 & 6.10 & 3.5 & 45.8 & 67.5 & 26.9 & 0.254 \\
1200 & 2.32 & 6.23 & 3.4 & 54.2 & 69.0 & 26.8 & 0.288 \\
1400 & 2.36 & 6.40 & 3.5 & 58.2 & 74.6 & 29.0 & 0.286 \\
1600 & 2.85 & 6.54 & 4.0 & 61.1 & 109.5 & 45.6 & 0.201 \\
1800 & 3.12 & 8.2 & 4.6 & 121.9 & 167.9 & 66.1 & 0.270
\end{tabular}

Таблица 3. Плотность $\rho$, скорости звука $V_{L}$ и $V_{T}$, объемный модуль $B$, модуль Юнга $E$, модуль сдвига $G$, коэффициент Пуассона $\sigma$ образцов, полученных из $\mathrm{C}_{60}$ при $2.0 \mathrm{GPa}$

\begin{tabular}{c|c|c|c|c|c|c|c}
\hline $\begin{array}{c}\text { Температура } \\
\text { синтеза, }{ }^{\circ} \mathrm{C}\end{array}$ & $\begin{array}{c}\rho( \pm 0.03), \\
\mathrm{g} / \mathrm{cm}^{3}\end{array}$ & $\begin{array}{c}V_{L}( \pm 0.06), \\
\mathrm{km} / \mathrm{s}\end{array}$ & $\begin{array}{c}V_{T}( \pm 0.03), \\
\mathrm{km} / \mathrm{s}\end{array}$ & $\begin{array}{c}B( \pm 1), \\
\mathrm{GPa}\end{array}$ & $\begin{array}{c}E( \pm 1), \\
\mathrm{GPa}\end{array}$ & $\begin{array}{c}C_{44}=G( \pm 0.4), \\
\mathrm{GPa}\end{array}$ & $\begin{array}{c}\sigma \\
( \pm 0.004)\end{array}$ \\
\hline 600 & 1.85 & 5.84 & 3.52 & 32.5 & 55.8 & 23.0 & 0.213 \\
800 & 1.86 & 6.52 & 3.88 & 41.8 & 68.8 & 28.1 & 0.224 \\
1000 & 2.02 & 6.47 & 3.95 & 42.6 & 75.6 & 31.4 & 0.204 \\
1200 & 2.08 & 6.52 & 3.90 & 46.3 & 77.2 & 31.6 & 0.222 \\
1400 & 2.14 & 6.22 & 3.72 & 43.4 & 72.55 & 29.7 & 0.221 \\
1600 & 2.19 & 6.25 & 3.85 & 42.1 & 77.5 & 32.5 & 0.192 \\
1800 & 2.19 & 6.32 & 3.94 & 42.1 & 80.4 & 34.0 & 0.182
\end{tabular}

высоком $(7.7 \mathrm{GPa})$ давлении, представлены в табл. 2. Плотность увеличивается с увеличением температуры синтеза с $2.19 \mathrm{~g} / \mathrm{cm}^{3}$ при $1000^{\circ} \mathrm{C}$ до $3.12 \mathrm{~g} / \mathrm{cm}^{3}$ при $1800^{\circ} \mathrm{C}$. Упругие модули растут и достигают следующих значений: $B \approx 122 \mathrm{GPa}, E \approx 167 \mathrm{GPa}, G \approx 66 \mathrm{GPa}$ при параметрах $7.7 \mathrm{GPa} / 1800^{\circ} \mathrm{C}$. Такое монотонное поведение модулей можно объяснить постепенным увеличением содержания алмазной фазы с увеличением температуры синтеза.

Как уже упоминалось, упругие модули для образцов, полученных из смеси $\left(31 \mathrm{wt} . \% \mathrm{~B}+69 \mathrm{wt} . \% \mathrm{C}_{60}\right)$ при давлении $2.0 \mathrm{GPa}$, достигают максимальных значений при температуре $800-1000^{\circ} \mathrm{C}$. При дальнейшем повышении температуры их значения снижаются (табл. 1). В то же время эти образцы, полученные при параметрах
$2.0 \mathrm{GPa} / 1000^{\circ} \mathrm{C}$, имеют более высокие значения модулей относительно образцов, полученных при $7.7 \mathrm{GPa} / 1000^{\circ} \mathrm{C}$ (табл. 2). Это, вероятно, обусловлено влиянием на модули дисперсной и/или рентгеноаморфной фазы карбида бора, которая проявляется широким $2 \theta=35-37^{\circ}$ гало на дифрактограммах. Эта рентгеноаморфная фаза, обладая высокими значениями упругих модулей, повышает механические характеристики всего композита. При этом она взаимодействует с углеродной составляющей, которая при $2.0 \mathrm{GPa}$ имеет первый дифракционный пик, смещенный в сторону меньших углов относительно пика 002 графита, а при $7.7 \mathrm{GPa}$ этот пик смещен в сторону больших углов.

Результаты, приведенные далее (табл. 3), свидетельствуют, что при обработке фуллерита $\mathrm{C}_{60}$ при $2.0 \mathrm{GPa}$ 
упругие модули непрерывно растут по мере повышения температуры с 600 до $1800^{\circ} \mathrm{C}$, при этом максимум при $800-1000^{\circ} \mathrm{C}$ отсутствует. Следует отметить, что значения упругих модулей, полученные для обработанного при давлении $2.0 \mathrm{GPa}$ фуллерита $\mathrm{C}_{60}$, коррелируют с результатами других авторов [12].

\section{Заключение}

Исследование трансформаций системы аморфный бор-фуллерит (31 wt.\% B + 69wt.\% $\left.\mathrm{C}_{60}\right)$ проведено при давлениях 2.0 и $7.7 \mathrm{GPa}$ в диапазоне температур $600-1800^{\circ} \mathrm{C}$, т.е. в областях, где алмаз соответственно термодинамически неустойчив и устойчив.

Показано, что при относительно низких парамет$\operatorname{pax}\left(\approx 2.0 \mathrm{GPa}\right.$ и в области $\left.1000^{\circ} \mathrm{C}\right)$ может быть получен нанокомпозит с достаточно высокими значениями упругих модулей: модуль объемного сжатия $B \approx 75.3-84.0 \mathrm{GPa}$, модуль Юнга $E \approx 108-119 \mathrm{GPa}$, модуль сдвига $G \approx 43-47 \mathrm{GPa}$, при плотности $\approx 2.2 \mathrm{~g} / \mathrm{cm}^{3}$. Такой набор характеристик, полученных при относительно низких параметрах синтеза, перспективен с точки зрения практического применения.

Установлено, что превращение фуллерита $\mathrm{C}_{60}$ при давлении $2.0 \mathrm{GPa}$ и повышении температуры с 600 до $1800^{\circ} \mathrm{C}$ происходит по схеме $\mathrm{C}_{60} \rightarrow$ разупорядоченный углерод, а при давлении $7.7 \mathrm{GPa}$ по схеме $\mathrm{C}_{60} \rightarrow$ разупорядоченный углерод $\rightarrow$ алмаз. Одновременно при соответствующих температурах углерод взаимодействует с бором, образуя карбид бора $\mathrm{B}_{4} \mathrm{C}$.

При давлении $2.0 \mathrm{GPa}$ и начиная с $\sim 800^{\circ} \mathrm{C}$ фуллерит $\mathrm{C}_{60}$ в системе (31 wt.\% B + 69wt.\% $\left.\mathrm{C}_{60}\right)$ превращается в разупорядоченный (фуллереноподобный) углерод со средним межплоскостным расстоянием на $8-11 \%$ больше, чем у графита. Эта фаза упорядочивается с повышением температуры до $1800^{\circ} \mathrm{C}$. А также при температуре $\sim 800^{\circ} \mathrm{C}$ появляется рентгеноаморфная фаза $\mathrm{B}_{4} \mathrm{C}$. При температуре $\sim 1200^{\circ} \mathrm{C}$ на дифрактограммах появляются пики кристаллического $\mathrm{B}_{4} \mathrm{C}$. При температуре $1800^{\circ} \mathrm{C}$ материал состоит из относительно упорядоченных графитоподобного углерода и карбида $\mathrm{B}_{4} \mathrm{C}$.

При давлении $7.7 \mathrm{GPa}$ и начиная с $\sim 800^{\circ} \mathrm{C}$ фуллерит $\mathrm{C}_{60}$ в системе $\left(31\right.$ wt.\% $\mathrm{B}+69$ wt.\% $\left.\mathrm{C}_{60}\right)$ превращается в разупорядоченный углерод, который имеет среднее межплоскостное расстояние несколько меньшее, чем у графита. При $\sim 1400^{\circ} \mathrm{C}$ на дифрактограммах появляется самый сильный пик 111 алмаза. Содержание алмаза растет с увеличением температуры синтеза. В результате взаимодействия бора и углерода при $1200^{\circ} \mathrm{C}$ появляется гало в области $2 \theta=35-37^{\circ}$. При более высоких температурах $\sim 1400^{\circ} \mathrm{C}$ в этой области появляются пики карбида бора $\mathrm{B}_{4} \mathrm{C}$. При температуре $1800^{\circ} \mathrm{C}$ материал состоит из матрицы $\mathrm{B}_{4} \mathrm{C}$ со встроенными в нее алмазами с размером частиц менее $1 \mu \mathrm{m}$, часть из которых находится в виде друз. В то же время по-прежнему присутствует небольшое количество относительно упорядоченного графитоподобного углерода.

В композитах (31 wt.\% B + 69wt.\% $\left.\mathrm{C}_{60}\right)$, полученных при $2.0 \mathrm{GPa}$, максимальные значения упругих модулей наблюдались при температурах синтеза в области $800-1000^{\circ} \mathrm{C}$. Это совпадает с формированием разупорядоченной фазы углерода, которая имеет фуллереноподобное строение, а также с образованием рентгеноаморфного соединения бора и углерода.

При более высоких давлениях $(7.7 \mathrm{GPa})$, при наличии в структуре алмазной углеродной составляющей упругие модули композита напрямую зависят от содержания алмаза в композите.

Работа выполнена с использованием оборудования ЦКП „Исследования наноструктурных, углеродных и сверхтвердых материалов“ (ЦКП ФГБНУ ТИСНУМ), поддержанного Минобрнауки России в рамках выполнения соглашения № 14.593.21.0007 от 28.08.2017, ID RFMEFI59317X0007. Авторы благодарят В.В. Аксененкова, Л.А. Иванова, И.А. Пережогина и Б.А. Кульницкого за помощь при проведении настоящей работы.

\section{Список литературы}

[1] Carbon Alloys. Novel concept to development carbon science and technology / Ed. by E. Yasuda, M. Inagaki, K. Kaneko, M. Endo, A. Oya, Y. Tanabe. Elsevier Science, 2003. 584 p.

[2] Blank V.D., Buga S.G., Serebryanaya N.R., Dubitsky G.A., Mavrin B.N., Popov M.Yu., Bagramov R.H., Prokhorov V.M., Sulyanov S.N., Kulnitskiy B.A., Tatyanin Ye.V. // Carbon. 1998. Vol. 36. P. 665-670.

[3] Talyzin A.V., Dubrovinsky L.S., Oden M., Jansson U. // Diamond Relat. Mater. 2001. Vol. 10. P. 2044-2048.

[4] Chernogorova O., Drozdova E., Ovchinnikova I., Soldatov A.V., Ekimov E. // J. Appl. Phys. 2012. Vol. 111. P. 112601-5.

[5] Bagramov R., Serebryanaya N., Kulnitskiy B., Blank V. // Fullerenes Nanot. Carbon Nanostruct. 2016. Vol. 24. P. 20 24.

[6] Harris P.J.F. // Philos. Mag. 2004. Vol. 84. P. 3159-3167.

[7] Khvostantsev L.G., Slesarev V.N., Brazhkin V.V. // High Pressure Research. 2004. Vol. 24. P. 371-383.

[8] Thevenot F. // J. Eur. Ceram. Soc. 1990. Vol. 6. P. 205-225.

[9] Bundy F.P., Bassett W.A., Weathers M.S., Hemley R.J., Mao H.K., Goncharov A.F. // Carbon. 1996. Vol. 34. P. 141153.

[10] Decker D.L., Bassett W.A., Merrill L., Hall H.T., Barnett J.D. // J. Phys. Chem. Ref. Data. 1972. Vol. 1. P. 1-79.

[11] Prokhorov V.M., Bagramov R.H., Blank V.D., Pivovarov G.I. // Ultrasonics. 2008. Vol. 48. P. 578-582.

[12] Brazhkin V.V., Lyapin A.G. // J. Superhard Mater. 2012. Vol. 34. P. 400-423. 